\title{
INFORMATION AS A GENERIC CONCEPT OF CERTAIN OBJECTS OF CIVIL RIGHTS (THE CASE OF DIGITAL RIGHTS)
}

\author{
Natalia S. Aleksandrova \\ Volgograd Institute of Management - Branch of Russian Presidential Academy of National Economy \\ and Public Administration, Volgograd, Russian Federation
}

Introduction: in the modern world, and, as a result, the legislation, society inevitably faces new phenomena that cannot always be successfully implemented in the existing database of the rules of substantive law. The paper deals with the concept of "information" in the retrospect of the civil legislation. The purpose of the paper is to study the concept of "information", as well as the objects of civil rights associated with this concept. The author focuses on "digital rights" as a new object of civil rights. Methods: the methodological framework is a set of methods of scientific knowledge, such as the method of scientific analysis and the comparative law method. The final part of the paper presents the arguments of modern civilists about the object of civil rights and its circulability. The results of the study are a well-founded point of view about the need to recognize information as a generic concept in relation to certain declared objects of civil rights. Conclusions: the scientific discussion regarding the removing of information from the list of objects of civil rights has objective reasons; the entering of information in the list of civil rights objects would eliminate some theoretical and practical contradictions.

Key words: information, digital rights, objects of civil rights, circulability, cryptocurrency.

Citation. Aleksandrova N.S. Information as a Generic Concept of Certain Objects of Civil Rights (The Case of Digital Rights). Legal Concept, 2020, vol. 19, no. 1, pp. 64-68. (in Russian). DOI: https://doi.org/10.15688/lc.jvolsu.2020.1.8

УДК 347.1

ББК 67.404
Дата поступления статьи: 15.01.2020

Дата принятия статьи: 05.02.2020

\section{ИНФОРМАЦИЯ КАК РОДОВОЕ ПОНЯТИЕ НЕКОТОРЫХ ОБЪЕКТОВ ГРАЖДАНСКИХ ПРАВ (НА ПРИМЕРЕ ЦИФРОВЫХ ПРАВ)}

\author{
Наталия Сергеевна Александрова \\ Волгоградский институт управления - филиал Российской академии народного хозяйства \\ и государственной службы при Президенте РФ, г. Волгоград, Российская Федерация
}

Введение: в условиях современного мира и, как следствие, законодательства общество неизбежно сталкивается с новыми явлениями, которые не всегда удается успешно внедрить в имеющуюся базу материальных норм закона. В предлагаемой статье рассматривается понятие «информация» в ретросформация», а также сопряженных с ним объектов гражданских прав. Автором сделан акцент на «цифровые права» как новый объект гражданских прав. Методологическую основу составляет совокупность м. методов научного познания, таких как метод научного анализа, сравнительно-правовой метод. В заключительной части статьи приведены рассуждения современных цивилистов об объекте гражданских прав 在 и его оборотоспособности. Результатом настоящего исследования явилась обоснованная точка зрения о необходимости признания информации родовым понятием по отношению к некоторым провозглашенным объектам гражданских прав. Выводы: научная дискуссия касательно исключения информа() ции из числа объектов гражданских прав имеет объективные причины; возвращение информации в 
перечень объектов гражданских прав позволит устранить некоторые теоретические и практические противоречия.

Ключевые слова: информация, цифровые права, объекты гражданских прав, оборотоспособность, криптовалюта.

Цитирование. Александрова Н. С. Информация как родовое понятие некоторых объектов гражданских прав (на примере цифровых прав) // Legal Concept = Правовая парадигма. - 2020. - T. 19, № 1. - C. 64-68. -DOI: https://doi.org/10.15688/lc.jvolsu.2020.1.8

\section{Введение}

Задачей настоящей статьи является анализ понятия «информация», соотнесение его с понятием «цифровые права», анализ возможности выражения информации в виде цифровых прав применительно к перечню объектов гражданских прав, закрепленных в ст. 128 Гражданского кодекса РФ [3] (далее - ГК РФ).

Актуальность выбранной темы подтверждается многолетней дискуссией в науке гражданского права, посвященной тому, является ли информация объектом гражданских прав сама по себе и целесообразным ли было исключение этого понятия из перечня объектов гражданских прав.

\section{Информация как объект гражданских прав}

Как известно, объектом гражданских прав выступают материальные и нематериальные блага, по поводу которых могут возникать, изменяться и прекращаться права и обязанности субъектов гражданского правоотношения, то, по поводу чего возникает гражданское правоотношение.

В гражданско-правовой науке тема объекта гражданского правоотношения традиционно вызывает дискуссии. Совокупность взглядов на заданную проблематику условно можно разделить на два крупных лагеря: монистический и плюралистический. Последователи плюралистических теорий полагают, что объектами гражданских прав могут выступать совокупности благ-вещи, услуги, личные блага и т. п. [4]. Представители монистических теорий настаивают на тезисе единства объекта, который выражается в виде действия или вещи [7, с. 125-126]. При этом плюралистические взгляды на объект гражданских прав позволяют отграничить одно право- отношение от другого - в зависимости от определения объекта [2].

С принятием Федерального закона «О введении в действие части четвертой гражданского кодекса Российской Федерации» от 18 декабря 2006 г. № 231-Ф3 [10] информация была исключена из перечня объектов гражданских прав, приводимого в ст. 128 ГК РФ.

В настоящий момент на смену понятию «информация» в перечне объектов гражданских прав появились цифровые права, оказание услуг, результаты работ, результаты интеллектуальной деятельности, находящиеся под охраной закона. Как видно, законодатель предпринял попытку отграничить «оборотоспособную информацию» из всего массива объектов, подпадающих под это понятие.

Тем не менее в целом ряде случаев, предусмотренных законом, оперирование информацией само по себе порождает права и обязанности. Как справедливо замечает Е.В. Богданов, «предоставление информации контрагенту нередко представляет собой необходимую меру для устранения дисбаланса интересов сторон, особенно в ситуациях, когда возникает конфликт между конкурирующими правами субъектов». Например, арендатор, находя недостатки в арендуемом имуществе, вправе требовать от арендодателя либо безвозмездного устранения недостатков имущества, либо соразмерного уменьшения арендной платы, либо возмещения расходов на устранение обнаруженных недостатков в соответствии со ст. 612 ГК РФ. Получив соответствующее сообщение от арендатора, арендодатель может либо компенсировать расходы на устранение выявленных недостатков, либо устранить недостатки самостоятельно, либо заменить объект аренды иным схожим имуществом. Таким образом, обе стороны уполномочены на совершение определенных действий: арендатор, к примеру, 
может самостоятельно устранить недостатки арендуемого имущества, запросив при этом возмещение понесенных расходов у арендодателя, а арендодатель, в свою очередь, вправе произвести замену объекта аренды на аналогичное исправное имущество, будучи соответственно проинформированным арендатором; в описанной ситуации явно прослеживается конкурирование прав сторон обязательства, которое устраняется вследствие информирования арендодателя о пороках объекта аренды. Пункт 1 ст. 612, п. 3 ст. 307, п. 3 и 4 ст. 1 ГК РФ в совокупности позволяют сделать подобное заключение. При этом в случае отсутствия соответствующего извещения подразумевается недобросовестность со стороны арендатора [1].

В соответствии с ч. 1 ст. 5 Федерального закона от 27 июля 2006 г. № 149-Ф3 «Об информации, информационных технологиях и о защите информации» [11] информация может являться объектом публичных, гражданских и иных правовых отношений. Таким образом, прослеживается явное противоречие между исключением информации из перечня объектов гражданских прав ст. 128 ГК РФ и признанием информации объектом правовых отношений Ф3 «Об информации, информационных технологиях и о защите информации».

\section{Цифровые права как объекты гражданских прав}

Данная проблема не нова и является предметом научных споров на протяжении многих лет. Однако в связи с введением в перечень объектов гражданских прав цифровых прав заявленная проблематика предстает в новом свете.

Согласно ст. 2 Ф3 «Об информации, информационных технологиях и о защите информации», информация - это сведения (сообщения, данные) независимо от формы их представления, а информационная система представляет собой совокупность содержащихся в базах данных информации и обеспечивающих ее обработку информационных технологий и технических средств.

В соответствии со ст. 141.1 ГК РФ «цифровыми правами признаются названные в таком качестве в законе обязательственные и иные права, содержание и условия осуществления которых определяются в соответствии с правилами информационной системы, отвечающей установленным законом признакам» [3].

Разумно предположить, что информация выражается в цифровых правах. Подобный вывод можно сделать и в отношении результатов оказания услуг, также перечисленных в перечне объектов гражданских прав, если предметом договора возмездного оказания услуг являлись, к примеру, сбор, анализ и представление информации о чем-либо, в частности о показателях средней зарплаты по заданной отрасли.

Если рассмотреть на примере такого выражения цифровых прав, как криптовалюта, соотношение их с понятием «информация», то взаимосвязь будет явная, поскольку криптовалюта технически представляет собой именно информацию в виде сложнозашифрованного компьютерного кода. В результате возможным является вывод о том, что понятие «информация» является родовым по отношению к понятию цифровых прав, которое является подчиняющимся и видовым по отношению к родовому.

Как отмечают А.П. Сергеев и Т.А. Терещенко, в условиях действующего законодательства возможность соотнесения информации с каким-либо из объектов, предусмотренных ст. 128 ГК РФ, определяет соответствующий гражданско-правовой режим информации. Таком образом, «при всем многообразии данных, которые обрабатываются с использованием современных технологий и имеют различные источники формирования, их гражданское регулирование формально не осуществляется, если невозможно применить один из существующих частных институтов (например, услуги, базы данных как объекты авторских или смежных прав, ноу-хау и т. п.)» [9].

Более того, как совершенно справедливо отмечают Т.В. Дерюгина и А.О. Иншакова, оборотоспособность объектов гражданских прав, исходя из действующей редакции ст. 129 ГК РФ, является условием существования объекта с точки зрения закона. Исключив из редакции названной правовой нормы упоминание об объектах, изъятых из оборота, по всей видимости законодатель исходит из того, что объектов гражданских прав, ко- 
торые не участвуют в гражданском обороте, не существует [5].

С другой стороны, ч. 1 ст. 5 ФЗ «Об информации, информационных технологиях и озащите информации» предусматривает, что «информация может являться объектом публичных, гражданских и иных правовых отношений», то есть приведенная норма является по сути диспозитивной и предусматривает, что информация может и не являться объектом права.

В последнее время в науке неоднократно отмечался рост нематериальных благ, по большей части в цифровой форме, которые могут повлечь за собой вытеснение привычных нам материальных объектов права из оборота [8]. Неслучайно современные цивилисты все больше внимания уделяют проблематике цифровизации в целом. Многие издания посвящают целые выпуски новым цифровым граням жизни и, как следствие, права. Так, финальный выпуск издания «Legal Concept = Правовая парадигма» в 2019 г. был посвящен проблемам, проистекающим из четвертой промышленной революции. Правовое регулирование принципиально новых явлений и объектов - процесс трудоемкий, обусловленный неизбежным конфликтом правовых режимов в той части, в которой они могут регулировать сопряженные объекты, или объекты, относящиеся к одному родовому понятию. Как замечает А.О. Иншакова, «в исследованиях правоведов основной целью теоретического характера становится разработка концептуальных основ правового регулирования технологий индустрии 4.0» [6].

Означает ли сказанное, что будь информация сохранена в качестве поименованного объекта гражданских прав, проблем с определением правовой природы цифровых прав было бы меньше? Думается, в условиях неопределенности это послужило бы хорошей отправной точкой при исследовании содержания понятия цифровых прав.

\section{Выводы}

Таким образом, несмотря на многолетнюю дискуссию относительно целесообразности исключения информации как объекта гражданского права, поименованного в перечне ст. 128 ГК РФ, проблема не теряет акту- альности и по сей день. Представляя собой фактически сложнозашифрованную информацию, криптовалюта как частное и цифровые права в целом являются специальным понятием по отношению к понятию «информация». Возвращение информации в число закрепленных объектов гражданского права позволило бы устранить озвученные теоретические противоречия, а также несогласованность Гражданского кодекса с Федеральным законом «Об информации, информационных технологиях и о защите информации».

\section{СПИСОК ЛИТЕРАТУРЫ}

1. Богданов, Е. В. Информация как объект гражданских правоотношений / Е. В. Богданова // Гражданское право. - 2018. - № 5. - С. 29-33.

2. Болтанова, Е. С. Генетическая информация в системе объектов гражданских прав / Е. С. Болтанова, М. П. Имекова // Lex russica. - 2019. - № 6. C. $110-121$

3. Гражданский кодекс Российской Федерации (часть первая) от 30.11.1994 № 51-ФЗ (ред. от 03.08.2018) // Собрание законодательства РФ. 1994. -5 дек. (№ 32). - Ст. 3301.

4. Гримм, Д. Д. К учению об объектах права / Д. Д. Гримм // Вестник права. - 1905. - № 7. С. 157-196.

5. Дерюгина, Т. В. Оборотоспособность и правовой режим объектов гражданских прав: соотношение понятий / Т. В. Дерюгина, А. О. Иншакова // Законы России: опыт, анализ, практика. - 2019. № 6. - C. 31-34.

6. Иншакова, А. О. Право и информационнотехнологические преобразования общественных отношений в условиях индустрии 4.0 / А. О. Иншакова // Legal Concept = Правовая парадигма. -2019. T. 18, № 4. - C. 6-17. - DOI: https://doi.org/10.15688/ lc.jvolsu.2019.4.1.

7 Пухта, Г. Ф. Курс римского гражданского права / Г. Ф. Пухта. - Т. 1. - М., 1874. - 550 с.

8. Сарбаш, С. В. Гражданский оборот в цифровую эпоху / С. В. Сарбаш. - Электрон. текстовые дан. - Режим доступа: https://zakon.ru/blog/2017/10/ 21/grazhdanskij_oborot_v_cifrovuyu_epohu\# comment_463987 (дата обращения: 05.07.2019). - Загл. с экрана.

9. Сергеев, А. П. Большие данные: в поисках места в системе гражданского права / А. П. Сергеев, Т. А. Терещенко// Закон. - 2018. - № 11. - С. 106-123.

10. Федеральный закон от 18.12.2006 № 231-Ф3 (ред. от 30.12.2015) «О введении в действие части четвертой Гражданского кодекса Российской Фе- 
дерации». - Электрон. текстовые дан. - Режим доступа: http://www.pravo.gov.ru (дата обращения: 05.01.2020). - Загл. с экрана.

11. Федеральный закон от 27.07.2006 № 149-Ф3 (ред. от 02.12.2019) «Об информации, информационных технологиях и о защите информации». - Электрон. текстовые дан. - Режим доступа: http:// www.pravo.gov.ru (дата обращения: 05.01.2020). Загл. с экрана.

\section{REFERENCES}

1. Bogdanov Ye.V. Informatsiya kak obyekt grazhdanskikh pravootnosheniy [Information as an Object of Civil Legal Relations]. Grazhdanskoe pravo [Civil Law], 2018, no. 5, pp. 29-33.

2. Boltanova Ye.S., Imekova M.P. Geneticheskaya informatsiya $\mathrm{v}$ sisteme obyektov grazhdanskikh prav [Genetic Information in the System of Civil Rights]. Lex russica, 2019, no. 6, pp. 110-121.

3. Grazhdanskiy kodeks Rossiyskoy Federatsii (chast pervaya) ot 30.11.1994 № 51-FZ (red. ot 03.08.2018) [Civil Code of the Russian Federation (Part One) dated November 30, 1994 No. 51-Ф3 (as amended on August 3, 2018)]. Sobranie zakonodatelstva RF [Collection of the Legislation of the Russian Federation], 1994, 30 November (no. 32), art. 3301.

4. Grimm D.D. K ucheniyu ob obyektakh prava [To the Doctrine of the Objects of Law]. Vestnik prava, 1905 , no. 7, pp. 157-196.

5. Deryugina T.V., Inshakova A.O. Oborotosposobnost i pravovoy rezhim obyektov grazhdanskikh prav: sootnoshenie ponyatiy [Turnover and the Legal Regime of Civil Rights Projects: Correlation of Concepts]. Zakony Rossii: opyt, analiz, praktika [Laws of Russia: Experience, Analysis, Practice], 2019, no. 6, pp. 31-34.

6. Inshakova A.O. Pravo i informatsionnotekhnologicheskie preobrazovaniya obshchestvennykh otnosheniy $\mathrm{v}$ usloviyakh industrii 4.0 [Law and Information and Technological Transformations of Public Relations in Industry 4.0]. Legal Concept $=$ Pravovaya paradigma, 2019, vol. 18, no. 4, pp. 6-17. DOI: https://doi.org/10.15688/lc.jvolsu.2019.4.1.

7. Pukhta G.F. Kurs rimskogo grazhdanskogo prava. T. 1 [Roman Civil Law Course. Vol. 1]. Moscow, 1874. $550 \mathrm{p}$.

8. Sarbash S.V. Grazhdanskiy oborot v tsifrovuyu epokhu [Digital Turnover in the Digital Age]. URL: https://zakon.ru/blog/2017/10/21/grazhdanskij_ oborot_v_cifrovuyu_epohu\#comment_463987 (accessed 5 June 2019).

9. Sergeyev A.P., Tereshchenko T.A. Bolshie dannye: v poiskakh mesta $\mathrm{v}$ sisteme grazhdanskogo prava [Big Data: Looking for a Place in the Civil Law System]. Zakon [The Law], 2018, no. 11, pp. 106-123.

10. Federalnyy zakon ot 18.12.2006 № 231-FZ (red. ot 30.12.2015) «O vvedenii v deystviye chast $i$ chetvertoy Grazhdanskogo kodeksa Rossiyskoy Federatsii» [Federal Law of December 18, 2006 no. 231FZ(as amended on December 30, 2015) “'On the Enactment of Part Four of the Civil Code of the Russian Federation"]. URL: http://www.pravo.gov.ru (accessed 5 January 2020.

11. Federalnyy zakon ot 27.07.2006 № 149-FZ (red. ot 02.12.2019) «Ob informatsii, informatsionnykh tekhnologiyakh i o zashchite informatsii» [Federal Law of July 27, 2006 no. 149-FZ (as amended on December 2, 2019) "On Information, Information Technologies and the Protection of Information"]. URL: http://www.pravo (accessed 5 January 2020).

\section{Information About the Author}

Natalia S. Aleksandrova, Postgraduate Student, Department of Civil Law Disciplines, Volgograd Institute of Management - Branch of Russian Presidential Academy of National Economy and Public Administration, Gagarina St., 8, 400131 Volgograd, Russian Federation, natalex034@gmail.com, https://orcid.org/0000-0002-6173-3676

\section{Информация об авторе}

Наталия Сергеевна Александрова, аспирант кафедры гражданско-правовых дисциплин, Волгоградский институт управления - филиал Российской академии народного хозяйства и государственной службы при Президенте РФ, ул. Гагарина, 8, 400131 г. Волгоград, Российская Федерация, natalex034@gmail.com, https://orcid.org/0000-0002-6173-3676 